\title{
Conversations in search of audiences: Prospects and challenges of marketing UK's postgraduate higher education using social media
}

\author{
Baomin Qi ${ }^{1}$, Amit Mitra ${ }^{2}$ \\ ${ }^{1}$ Bolton Business School, University of Bolton, Bolton, UK \\ ${ }^{2}$ Bristol Business School, University of the West of England, Bristol, UK \\ Corresponding author: Amit Mitra (Amit.Mitra@uwe.ac.uk)
}

\begin{abstract}
It is no surprise that there are serious disparities between the rhetoric of education and the realities of education. Marketing of university curricula is a challenge that is increasingly becoming a difficult proposition as advances in social media (SM) are enabling prospective students to form opinions and inform their decisions like never before. Whilst the Universities and Colleges Admissions Service (UCAS) plays a central role in matching undergraduate students to courses in universities yet the same does not apply to postgraduate admissions which are sought after by a large number of applicants from overseas as well. This paper looks at some of the areas where SM has been successfully used. The papers then goes onto develop taxonomy of popular SM tools that are being widely used. Using this taxonomy it explores barriers and promoters that exist in the interface between universities and their audiences.
\end{abstract}

Keywords: Social media, higher education, postgraduate, online conversation, online marketing

\section{INTRODUCTION}

About a couple of decades ago nobody expected to measure popularity by the number of Facebook friends one had. Whilst people find less time to meet each other in the real world they seem to be drawn towards spending more time in the virtual community of social media. Visiting shops on the high street, talking to sales staff about features of products seem to have been replaced by reviews and experiential accounts of fellow social media punters. Ubiquitous online access through different interfaces has brought about a world where consumption of goods is prefaced by surveys and recommendations of friends and family. Reliability of views of friends and family seems to have assumed a special significance where sellers increasingly use viral marketing to inform the world of products and services. Lack of time to speak to high street salesmen seems to have been replaced by an abundance of views within social media platforms. The advent of such a resource that potentially enriches prospects of product sales has influenced many customer-facing businesses to consider ways of reaching out to potential markets through a dynamic personalisation of products and offerings.

At a time when being social may mean being active online, it is obvious that for Higher Education Institutions (HEIs) to cultivate audiences may require consistent engagement with participants on social media platforms. As more people are registering on social media sites, we are gradually moving towards a mature social media usage environment. Whilst in the late 1990s use of social media platforms like Facebook was taken to be a must have, the advent of recent protest movements, its use for anti-state activities, as well as becoming infamous for being a ploy for time wasting, has relegated possession of a Facebook account to a 'could have' status. For instance, one does get to hear tales of employers declining jobs to prospective candidates if they are known to be active Facebookers. However, with the progress of technology, ubiquity of the online world has meant that an ever increasing number of people are now accessing social media platforms through a variety of interfaces like smartphones and tablets. In a context where opinions and reviews are central to generating stickiness and market share, HEIs would be an exception if they were to overlook opportunities to market their offerings through social media platforms. Just like creating a website with goods and services does not mean that eCommerce traffic can be successfully generated by it, similarly engagement and mediation are imperative to successfully develop audiences that could then be converted into market share for HEIs.

In a fiercely competitive recruitment market, uniqueness of offerings can be a key differentiator that enables a university to not be beaten on price. Given the ability of social media platforms to enable a two-way communication, it is feasible that fulfilment maybe more easily attainable in comparison to platforms devoid of SM links. It is often argued that marketing communications will be a differentiating feature that an institution can offer its potential students and the diverse promotion and marketing could be a key driving factor to the 
sustainable success of the HE sector [40]. The recent phenomena of social media (SM) technologies provides a potential solution to ensure the two-way communication with prospective students, who, especially in an increasingly competitive market place, want and indeed expect to feel valued. As [15] points out an overwhelming student preference seem to be to make up their own minds through bespoke searches of online offerings. They actively seek out institutions that understand their needs and can facilitate them in achieving their aspirations [3]. Thus, HEI's should be looking at new ways of communicating with students and try to build better relationships with them. With a proliferation of search tools and recommendation engines, audiences are wary of actually losing their ability to customise products. By facilitating a personal comment sharing platform it is likely that some of informal communication will add to a better management of expectations.

Many universities have already broached the concept of using SM to communicate with potential students. It is clear that more recently evolved universities require innovative mechanisms to attract and sustain audiences. According to [1], "Edge Hill University was one of the first HEIs in the UK to exploit social networking services such as Facebook.” They used this platform to raise their profile among the targeted student base in order to create a 'buzz' about their institution and also to engage in two-way communication with new, existing and past students. However, the social media arena is deemed by many HEIs as frivolous, and the significance of SM is yet to be widely realised. Though, recent statistics reveals that social networking and blog sites are now more popular than e-mail as a means of social communication, indeed they eclipsed email in global reach at $68.4 \%$ vs $64.8 \%$ in February 2009. [24] also identified that $40 \%$ of respondents of a study undertaken by Oracle believe that social networking is now easier to utilise than software currently adopted in the workplace. The following table is an attempt to classify some well-known SM tools that are used by audiences to gauge market opinion at the same time be able to consolidate public opinion through viral discussions.

Table 1. Taxonomy of social networking tools

\begin{tabular}{|c|c|c|}
\hline Activity & Tools & Influence/uptake \\
\hline Viral informal platform & Facebook, Bebo, MySpace & $\begin{array}{l}\text { Early adoption by vast numbers, successful } \\
\text { in quick mobilisation of public opinion. }\end{array}$ \\
\hline Professional networking & LinkedIn, Ning, Ecademy, & $\begin{array}{l}\text { Popular professional networking tools that } \\
\text { seems to have motivated people across a } \\
\text { multiple range of professions to set up links. } \\
\text { To some degree it may be said that new } \\
\text { expectations have been created by the } \\
\text { advent of these networking platforms. }\end{array}$ \\
\hline Blogging & 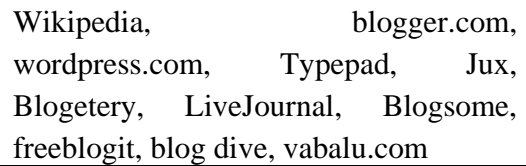 & $\begin{array}{l}\text { Situational commenting has led to the } \\
\text { creation of repositories that lead people to } \\
\text { express their views within readily accessible } \\
\text { platforms. }\end{array}$ \\
\hline Microblogging & $\begin{array}{l}\text { Twitter, Tumblr, Posterous Spaces, } \\
\text { Thoughts.com, Typepad Micro }\end{array}$ & $\begin{array}{l}\text { Instant communication within the world at } \\
\text { large within a defined character set that can } \\
\text { enable commenting on dynamic activities. }\end{array}$ \\
\hline Content management systems & Weebly, Moonfruit, Squarespaces & $\begin{array}{l}\text { Website development tools that can be used } \\
\text { to launch a business. Not much use as SM } \\
\text { tools. }\end{array}$ \\
\hline Video sharing & YouTube & $\begin{array}{l}\text { Widely used to provide snapshots of } \\
\text { work/profile. Especially beneficial when } \\
\text { performing arts types of courses are being } \\
\text { considered. }\end{array}$ \\
\hline Audio sharing & iTunes, Podcast.net & $\begin{array}{l}\text { Audio feature compositions on specific } \\
\text { topics can be listened to by audiences. }\end{array}$ \\
\hline Live-casting & BlogTalkRadio, Live 365 & $\begin{array}{l}\text { Live transmission of real time debates and } \\
\text { conversations, Tends to work best when } \\
\text { issues are topical and directed. }\end{array}$ \\
\hline Virtual worlds, Avatars & Second Life & $\begin{array}{l}\text { So far have been used to facilitate game } \\
\text { playing environments }\end{array}$ \\
\hline
\end{tabular}


The term 'social web' and Web 2.0 are often used interchangeably. These terms incorporate social networking sites (e.g. Bebo, Facebook, LinkedIn, MySpace, Ning, etc), Blogging sites (e.g. Blogger.com, Wikipedia and Wordpress) as well as micro-blogging sites (e.g. Twitter). Such an umbrella may also include Video (e.g. YouTube), Audio (e.g. iTunes and Podcast.net) and live-casting (e.g. BlogTalkRadio and Live 365), and the virtual worlds (e.g. Second Life). This clearly outlines the complexity surrounding the term social media, however the one commonality between all of the above areas is that they all focus on building online communities within which people interact and influence each other. For the marketer the adoption of social media marketing tools will require a paradigm-shift, as [39] illustrates “...the marketer's role changes from broadcaster pushing out messages and materials to an aggregator who brings together content and enables collaboration with communities." Although there are numerous articles written regarding the power of social media marketing, yet the literature is embryonic with regard to the public sector in general and the Higher Education sector in particular. Besides, as [6] has identified marketers in the public and private sectors to have considerably differing viewpoints on the relevance and importance of social media.

\section{OPPORTUNITIES FOR SOCIAL MEDIA ADOPTION}

[33] well known work entitled 'Screw blackboard... do it on Facebook' demonstrates some of the lack of reverence that the student community has towards structured engagement. Also given that many prospective students based overseas are going to only have access to Facebook it is likely that many interesting discussions could be had using it. The continued development and growing integration of social media technologies into many activities presents numerous hitherto non-existent opportunities for institutions to engage with the virtual community [30]. They allow prospective students to "...self-evaluate, self-segment, self-support, self-organise, self-advertise, self-police, and self-program...” [34:11]. If HEIs do not adapt their teaching, learning and research practices in order to engage with students and potential students on the social media, they could easily be usurped by their competitors. The following sections will explore available opportunities that institutions may use to develop competitive advantage.

\subsection{Experience sharing with current students}

[38] concurs that social media enables powerful feelings to be shared immediately with friends, colleagues, acquaintances and the general public. By setting up social networking sites and encouraging current students to write blogs about their experiences in universities, provides prospective students with an authentic student-tostudent communication platform on 'real' life as a student and what to expect [1]. It is therefore possible to enable students to feel part of the university community even before formally starting university life. Add to the social media's ability to build 24/7 virtual communities that share experiences, it is also feasible and particularly useful for an overseas student to access recommendations and feedback left by current and graduating students about an institution without leaving their home country.

From the literature review, what is also evident is that social media is here to stay, and people are empowered from utilising the internet and specifically social media sites, that provide free access to user-generated information. Though when enabling these channels, institutions should monitor currently active conversations and respond and engage as appropriate [11]. This is a particularly delicate issue as negative student feedback can quickly go out of control and situations can be easily blown out of proportion. The authors have experience of seeing Facebook pages created by students on why they consider certain lecturers to be unpopular. Just like fan mail of popular lecturers can sometimes have little to do with the actual content of the lecture and may be more with how somebody is perceived similarly unflattering comments can sometimes make tutors demons where subject itself might not be riveting material.

[37] observes that the social media arena is rapidly expanding, with innovative applications developing on an almost daily basis; with some institutions using tools such as Twitter to collate student opinion on tangible facilities on campus. Indeed, [37:37] identifies that "...Twitter is continuing to grow in popularity and evolve as both a social network and marketing tool..." Furthermore, individual's usage of Twitter varies presenting new marketing opportunities. However, it would be prudent for institutions to have identified who they are communicating to, what they are trying to communicate and which medium they wish to communicate on prior to communicating on these platforms [17]. 
Although HEI's have the platform to promote their achievements, this is not always effective. It would be more meaningful for them to encourage students to promote their successes. This is primarily because the student is the most transparent tool to deliver an honest review of life from within the institution [20]. Besides, the social media tools enable real time sharing of reactions and responses from individuals within that community [38]. In a way this makes it tricky for institutions as a balance needs to be struck between positive long term views on student experiences and the individual here and now snapshots.

\subsection{Word of mouth marketing and brand building}

[32] argue that social networks are ultimately creating influence among students. By developing and cultivating these networks, HEIs are able to create an opportunity to nurture the trust that results in increased numbers. Indeed, [11] have highlighted that "... 26\% of marketers say that social networking and word of mouth activities are the most likely marketing activity to increase ...” This is corroborated by [12] who believes that social networking and proximity marketing will be increasingly utilised in order to deliver targeted offers, generating word-of-mouth recommendations. [12] expects that increasing overlaps between social networking and proximity marketing in the near future that will enable further experimentation by marketers and brand managers.

Evidently, [21] identified that individuals are more inclined to believe information received from a word-ofmouth source. This is because such sources are the only ones that are from customers, by customers and for customers. In a social media context due to the personal nature of the environment participants feel encouraged to comment on personal experiences. Once collated these then may become significant vehicles to influence future participants. Thus there is no hidden agenda and so future students feel that the information contained therein is transparent. However, with this point in mind, HEIs need to be careful when trying to transfer wordof-mouth into the online social arena. Within such an arena the content being primarily controlled by the customer and therefore if the customer was dissatisfied in any way, implications of spreading unflattering messages may be serious.

A common feature of social networking is that individuals are drawn to those who have similar interests and/or behaviour to their own [23]. Thus, using social media to bring like-minded people together to discuss about their experiences on institutions could aid the building of brand awareness and raise the profile of the institution. Indeed, [13] highlighted that many HEIs have realised the potential benefits of e-recruiting after applicants converted to registered students through a continued electronic dialogue and consistent communication. Clearly such innovation can only consolidate the success of the HEIs. [35] also concurs and goes on to add that engaging in social media would involve customising the communication that will then engage the student, building trust and loyalty and thus embrace its potential as a tool to encourage a community ethos among students.

If an HEI leveraged its influence effectively across a mix of social media (i.e. micro-blogging, blogging and a presence on social network sites) they could wield considerably seductive marketing and branding system [22]. Such an approach will assume importance as traditional blanket marketing campaigns will get substituted by audience preferences of personalised conversation enabled through social media [29].

\subsection{Market Research:}

[19] has identified that “... social networking enables institutions to discover not just the answers to their questions, but the answers to questions they'd never thought of asking - that's both customer service at its best and a marketers dream...” This issue was reiterated by in [7]) who noted that in order to identify which market segments would be most profitable, market research would be essential. Indeed, without market research it would be difficult to know what the appropriate marketing mix would be for the segment, whether the information content would appeal to them and which media would be most effective in reaching them, consequently resulting in generating user demand.

Admittedly, Social Media may be deemed to be a direct and cost-effective market research tool for educating HEI's on identifying their customer base [25]. For instance, by using a YouTube channel to upload promotional videos, HEIs would be able to reduce costs of newspaper, radio and TV coverage [5]. Furthermore, [11] have identified that "...as more businesses integrate social networking sites into their digital marketing media mix, 
companies are increasingly focusing on measurement techniques to better understand the return on investment from social media.." Given financial constraints that are to be placed on HEI's in the future, cost-savings across all areas of the institutions will be essential.

Indeed, as a market research tool social media and the analytical tools that can be adopted should enable HEI's to not only listen to what is currently being said about their programmes and services, but also to engage with these conversations. By gathering data on the targeting and segmentation of their messages, they will be able to customise communications to specific platforms and to flexibly determine which platforms they should have a profile on. [9:7] has identified that "... social media is the word on the street, proof of bragging, culture and shortcuts..." Hence, the more profiles HEI's have the more they will be able to raise their brands and drive traffic to their main sites.

Having reviewed the available literature, Table 2 summarises, by embracing the social media technologies, the main opportunities that are presented to HEIs.

Table 2. Key opportunities of SM applications for HEIs

\begin{tabular}{|c|c|c|}
\hline Experience sharing & $\begin{array}{l}\text { Direct marketing and building brand } \\
\text { awareness }\end{array}$ & Market research \\
\hline $\begin{array}{l}\text { SM removes barriers and encourages } \\
\text { conversations between prospective and } \\
\text { current students } \\
\text { SM engages in two-way communication } \\
\text { between institutions and prospective } \\
\text { students } \\
\text { SM enables powerful feelings to be } \\
\text { shared immediately with friends, } \\
\text { colleagues, acquaintances' and the } \\
\text { general public } \\
\text { SM is ultimately creating influence } \\
\text { among students, by developing and } \\
\text { cultivating networks and if HEis can } \\
\text { influence the flow of conversation they } \\
\text { will have achieved a significant } \\
\text { competitive advantage } \\
\text { SM can enable potential students to join } \\
\text { the institution with an understanding of } \\
\text { the culture and expectations that they } \\
\text { may encounter }\end{array}$ & $\begin{array}{l}\text { SM can be used to build brand awareness } \\
\text { and raise the profile of the institution. } \\
\text { SM helps reach hundreds of millions of } \\
\text { targetable consumers } \\
\text { SM simplifies content management } \\
\text { systems and increases the overall quality } \\
\text { and effectiveness of marketing messages } \\
\text { SM enables HEIs to co-opt staff, existing } \\
\text { and former students to provide a realistic } \\
\text { image of the institution, its people and } \\
\text { environment } \\
\text { SM is rapidly expanding, with more } \\
\text { innovative applications developing on an } \\
\text { almost daily basis } \\
\text { Perception that information gained via } \\
\text { social networks is more trustworthy than } \\
\text { information that is only available from } \\
\text { the corporate hymn sheet }\end{array}$ & $\begin{array}{l}\text { Social Media has to be the purest, direct } \\
\text { and cost-effective market research tool } \\
\text { for educating HEI's on their customer } \\
\text { base } \\
\text { By gathering data on the targeting and } \\
\text { segmentation of their messages, HEIs } \\
\text { will be able to tailor the } \\
\text { communications to specific platforms } \\
\text { and to identify which platforms they } \\
\text { should have a profile on } \\
\text { Social media tools enable real time } \\
\text { sharing of reactions and responses from } \\
\text { individuals within that community } \\
\text { Social networking and proximity } \\
\text { marketing will increasingly overlap in } \\
\text { the coming years which will enable } \\
\text { more experimentation by marketers and } \\
\text { brand managers } \\
\text { Tools such as Twitter could be used to } \\
\text { collate student opinion on the tangible } \\
\text { facilities on campus }\end{array}$ \\
\hline
\end{tabular}

\section{CHALLENGES TO SOCIAL MEDIA ADOPTION}

Much has been written about the wonders of social media adoption, however as [13] has identified there are a number of institutional barriers to adoption within this sector such as, lack of horizontal communication, functional specialism, and decentralisation, lack of planning and expertise, lack of budget, lack of integration with Content Management Systems (CMS), corporate culture and fear of change.

\subsection{Internal issues impacting adoption}

The need for academic buy-in to new technologies is not a new phenomena, though as widely acknowledged that for many, too little time to learn new technologies is an issue. Moreover, [18] identified that within institutions “....35\% don't track any conversions, 32\% do with admissions info inquiries (47\% wish they did) and $29 \%$ with online applications (44\% wish they did)...” 
Understanding the role of innovative technologies with regard to skill development of staff is exceedingly important. How can an institution expect academic colleagues to participate and champion the use of new media, if they have not been given the opportunity to develop their skills in this area? Further for those who have used social media platforms for engagement are aware of impulsive potential of negative feedback generation and may be reluctant to integrate social media as a front line marketing tool in place of obtaining traditional avenues.

According to the [10] it will become the role of the marketing departments to become facilitators that aid the entire institution to realise that transparent, open communication and excellent customer service with their potential and existing market is essential to their continued survival. Besides, [8] believes that if marketing is to be utilised as an agent of change, then it must first demonstrate that it understands and empathises with the essence of Higher Education generally and second the individual characteristics and cultures of individual institutions. There is preponderance among HEIs to have marketing departments that are not sufficiently integrated with academic programs. Hence there may be a disconnect between agendas of academic programme directors and marketing groups.

As mentioned previously, [13] has identified a number of institutional barriers, not least that of culture. The cultural barriers- as with any innovation, is often a formidable challenge. For instance, regardless of the numerous successful social media platforms, many individuals remain sceptical of the value of investing time on these arenas and have voiced concerns regarding the perceived risks associated with adoption of such technologies [22]. Academics in HEIs are usually driven by individual goals and norms - carrying out their tasks. Use of social media platforms has an expectation of a group norm and collective endeavour. The latter might be alien and unattractive to existent traditional mind sets.

[23] reported that management often does not fully appreciate the role of social media within an institutions promotional arsenal. Indeed, “...the Higher Education sector is one that should be at the forefront of Twitter use and innovation, but which instead has been slow to adopt this technology..." [37:63]. HEIs that are deemed to be progressive tend to claim that they are enabling social media within their programs. However, they may not necessarily use it as a tool to attract and sustain audiences of prospective students. This is regardless of the fact that it magnifies the significant impact of customer-to-customer communication within the virtual marketplace and as yet they have not been able to articulate how to shape these communications in the future.

This is corroborated further by [20] who concur that adoption will be unsuccessful without the backing of the Managing Board within the HEI; who in turn would require a substantial business case to encourage investment. Although individuals may be convinced of the potential benefits, this alone is not enough. This is further exacerbated as "... marketing and academia are seen as diametric opposites in terms of both character and purpose..." [8:30], which again reiterates the importance of garnering support from the top of the institution down. There may also be HEIs that have its top management interested in implementing social media capacity but may not have a plan to implement as they themselves are not users of social media. Consequently academics may be daunted by the challenges to develop capacity in the absence of any official allocation of time for such activities.

It is apparent that many academics and other staff are not overtly predisposed to engaging with online communities. In keeping with the availability of new technology, it is a part of the expected norm for teaching staff to continually upgrade delivery of modules. Consequently, it is commonplace to find a much higher amount of technology enhanced interactivity between students and staff in comparison to delivery frameworks of the past. This sort of continued pursuit of technology enhancement tends to produce a kind of indifference among academics who perceive that as long as a one to one relationship works to facilitate module delivery, external effort to be part of a one to many relationships is probably an additional capacity feature that may or may not add to the student experience. This type of institutional inertia by staff is a significant barrier to adoption of social media, however the risk from doing nothing and being left behind is much higher than from doing something [1]. 


\subsection{Absence of policy and legal guidelines}

[22] argue that HEI's are struggling with the legal ramifications of embracing this new push for interactivity, clearly there are a minority who embrace innovation and have taken steps to deal with the challenges with which they are now faced, but it should be remembered they are a minority.

Many staff within HEIs are reluctant to embrace the technology fully, for fear of opening themselves to law suits due to lack of a clear policy. However, this can be addressed by developing guidelines and policies for using the tools. Indeed [11], have identified that the UK Consumer Protection from Unfair Trading Regulations 2008, provide information on legal requirements for transparency whilst online and using social media; this could be incorporated into policies and guidelines that HEIs produce.

Furthermore, HEIs often find themselves in a dilemma regarding the need to develop institutional on-line social networking policies [14]. Given the speed at which this arena is evolving there is not always sufficient time for universities to develop succinct policies on its use [1]. As universities become more driven by the need to sustain quality standards, the need for honest feedback from students is assumes importance. Whilst formal feedback generation is useful in ensuring the right levels of delivery specification is adhered to yet informal feedback like that available on social media platforms may have genuine substance. Ironically it is lack of clear policy that is impacting on adoption the most.

Moreover, HEIs need to remember that customer-to-customer communication can work both ways and as a result social network sites can also pose a threat, especially if a dissatisfied customer chooses to spread their views [29]. For example, members who perceive themselves to being tricked and who may not have received expected levels of transparency may have become dissatisfied very quickly, an event that would not prove beneficial to the institution. Especially given that “... increasingly students will formulate their opinions of a potential university on the feedback they receive on such sites from current students..." [30:15]. Somehow the juxtaposition of current student opinion with that of prospective students makes it an ongoing long term challenge for HEIs. Clearly it is an issue of considerable challenge for HEIs when they have to demonstrate the seriousness with which they treat current student feedback, if they are to rely on transmission of positive stories by current to prospective student audiences.

\subsection{Lack of understanding of the medium}

It is evident that many HEI's have a presence in the social media arena; it is equally evident that such a presence remains underutilised. Furthermore, many feel that having a presence on these platforms is intrusive and does not realise the potential first hand conversation advantages can offer [16]. Indeed, some sceptics believe social media is no more than a digital mailing list. Again, overlooking the opportunities it offers to share and comment on topics, and what an effective marketing communications tool it can actually be if utilised effectively [38].

There is also a significant gap between the potential of the technologies available and the manner in which they are currently being utilised [35]. For example, some HEIs use social networking to deliver learning, whilst other academic colleagues use it to interact with groups of students that are brought together. However, this has led to allegations of bullying or intimidation by staff and student alike [1]. [30] believes that if an institution has a reputation for academic collaboration, it would seem inevitable that a small number of individuals will already be communicating using these technologies. The following table 3 articulates the phases through which the marketing/recruitment activities may be mapped on the social media landscape.

Table 3. Mapping of information/feedback on various stages of the recruitment process

\begin{tabular}{|c|c|c|c|}
\hline Stage & Activity & Type of information & Prospective student perspective \\
\hline 1 & $\begin{array}{l}\text { Matching of expectations } \\
\text { with availability }\end{array}$ & Courses on offer & Actual content needs to fit with student interests \\
\hline 2 & $\begin{array}{l}\text { Assessment of attainment } \\
\text { at point of entry }\end{array}$ & $\begin{array}{l}\text { Pre-requisites to enrol on the } \\
\text { course }\end{array}$ & $\begin{array}{l}\text { Background information may enable students to } \\
\text { have a clear fit as well as enable comparison of } \\
\text { notes on strengths and weaknesses }\end{array}$ \\
\hline 3 & Finances & Fee levels/Costs & Best value/ Convenient payment arrangements \\
\hline 4 & Reputation & Feedback of past students & $\begin{array}{l}\text { Reiteration of value derivation in pursuit of the } \\
\text { course }\end{array}$ \\
\hline
\end{tabular}




\begin{tabular}{|l|l|l|l|}
\hline 5 & Prospects & $\begin{array}{l}\text { Job prospects and associated } \\
\text { advantages }\end{array}$ & $\begin{array}{l}\text { Job prospects in the market post completion of the } \\
\text { course }\end{array}$ \\
\hline
\end{tabular}

It is clear from table 3 above that social media can enable the recruitment process substantially as conversations around each of the stages may enable prospective students to appreciate the process of entry into a HEI through evaluation of what contributors on social media platforms may say. Both students within the UK as well as those without need specific information in the first instance and then assurances on that information to ensure that they are making meaningful choices that would have some kind of return on investment. Specific strengths of courses may enhance marketability through social media conversations. Further social media platforms like LinkedIn may be able to bring together opportunities in the job market as well as introductions of networks that may facilitate further addressing of aspirations of prospective students. More disturbingly, it has also been alleged that some HEI's have used their presence on these platforms to 'snoop' on how students are presenting themselves. Such activity can be potentially damaging and does little to develop a community of trust and transparency. Indeed, [31] has identified that for many the use of social media as a marketing tool in HE is controversial, added to this is of course ethical implications of how and what institutions are communicating with individuals. Moreover, some individuals see this method of communication as intrusive and if institutions get it wrong it can be an instant turn off [27].

The audiences using the social network arena are more educated and are no longer predisposed to accept every message a marketer wants to foist on them [12]. Rather, they will extract information that matches their needs and interests. According to [38:17] “...this can work two ways for marketers - some people will respond to direct engagement that cuts through the clutter. Others will instead ignore your noise alongside everyone else marketing a product or service...”

In order to gain competitive advantage from utilising social media technologies, HEIs need to implement proper market segmentation and positioning [4]. Figure 1 below presents this to enable visualisation of the intersections of student interests and how a specific target student audience can be located. However, this would prove difficult if staff do not understand the medium they are now delving into. Indeed, human nature dictates that we are often fearful of situations we don't understand and thus often allow others to venture out before us [32]. However, on this occasion, this type of strategy could prove extremely risky for the HEI and result in them being left behind. 


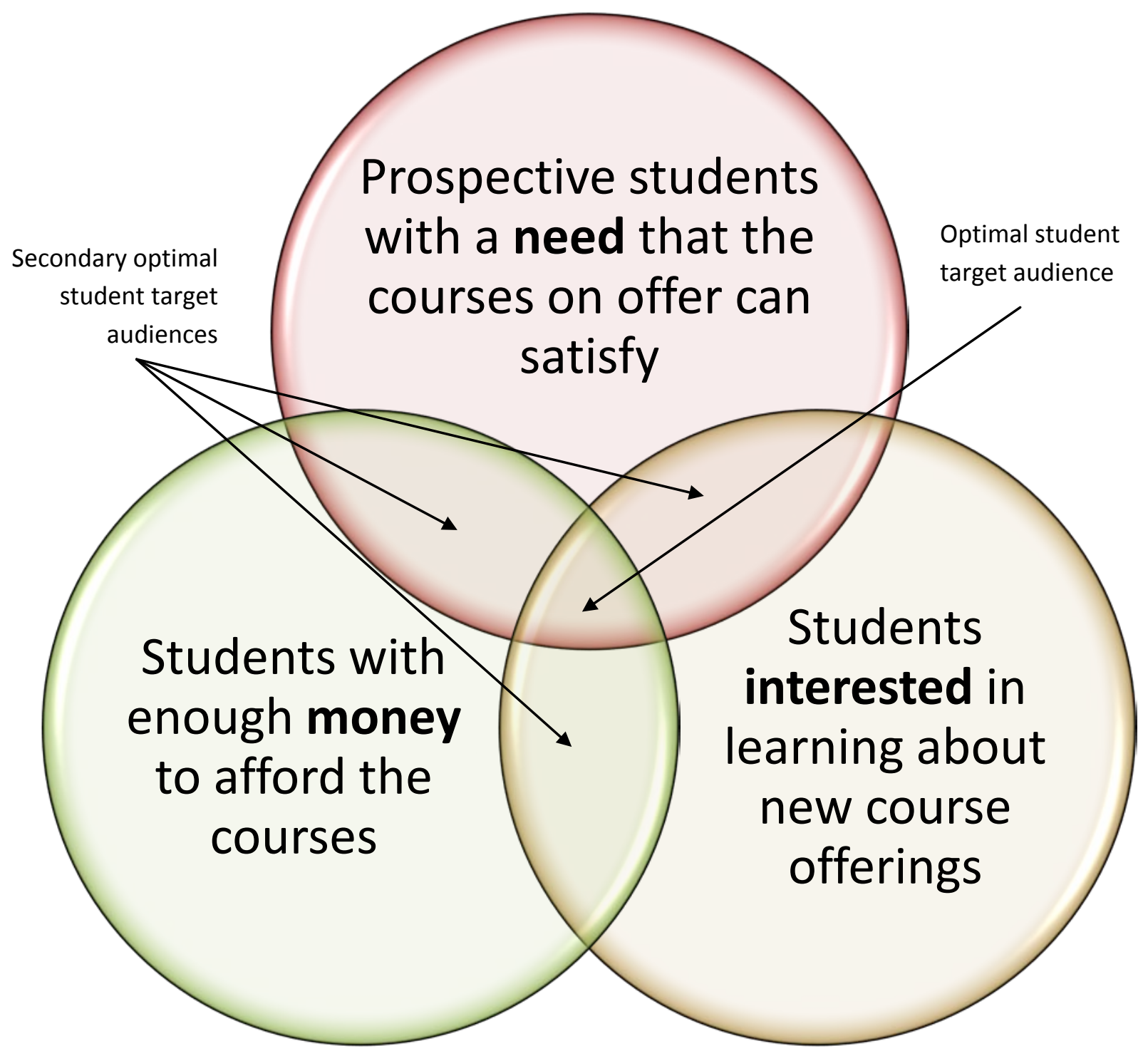

Fig. 1. Relationship between types of student expectations Source: Adapted from [2]

It is equally apparent that many within this sector are still uncertain about the lifecycle of this phenomena as well as implications of engagement. This was corroborated by [28] who identified that HEIs are struggling with what information and content is suitable for incorporation in social media (such as Twitter), whilst also trying to come to terms with how these mediums work. Although no one could argue that tools such as Twitter are not powerful additions to the social media marketeers toolkit, this would only be the case if utilised with a specific focus and end goal in mind.

[19] (2011:29) posits that “...with each person having an average of 130 friends on Facebook, negative word of mouth spreads faster than ever...” Moreover, [26] believes that although social networks may increase word of mouth they should not be used as a substitute of the personal touch but as an added value. For instance, what would be the point of being on twitter if you are not investing time in expanding your audience by getting others involved in the communication?

Individuals are often resistant to change and their norms “....are influenced by the cultural and situational surroundings and the behaviour norms and attitudes of their peers, who frequently have difficult barriers to change to overcome, or who are simply not motivated to change..." [10]. This is by far the most difficult challenge to overcome. Furthermore, institutions would be foolish to implement an all out attack on social 
media market share. Within the arena the onus is on starting small, monitoring the platforms to identify what suits your audience and focus on the long-term strategy on engagement [10].

\section{CONCLUSION}

The virtual world is now all around us and its reach knows no bounds across the globe and HEI's have recognised this shift in focus. At a time when geography has become an irrelevance, making choices for postgraduate programmes could benefit through conversations that are outside the normal realm of formal document based information. It is apparent that the driver to engage with social media is very much based on student expectations and motivations, regarding accessing information and communication. The concept of adopting social media marketing is still in its infancy for HEI's, although many early adopters have been dallying with this medium for some time, it has only recently garnered its current increased following and thus truly risen to the attention of HEI's. This taxonomy presented in this paper has identified numerous applications that fall under the 'social media' umbrella, including social network sites such as Facebook as well as blogging sites such as Twitter. However, it would be prudent to highlight that these media are far more successful and beneficial when used in conjunction with each other and not exclusively. Therefore, for a HEI to truly raise its profile and create a buzz within these arenas, they need to have a multi-faceted action plan that meets their institutional goals. Also if they wish to raise their profile and create a 'buzz' about the institution, they shouldn't first establish which social media applications their customer base are currently using and the focus should primarily on fostering long-term relationships that will build trust and credibility.

It is clear that there is a crying need to address informal conversations that could support standard admission procedures within the postgraduate market. By being able to engage in narratives of student expectations and what the HEI is trying to deliver it is likely that a human face of the organisation would be identifiable by the student community. As graduating students can sometimes be the inspiration for newer students, validation of perceptions gained through other means could be developed through personalised conversations that a social media tool like Facebook enables.

It is also evident that for social media marketing to be successful and thus beneficial to the institution, compatibility with the content management systems within the HEI is essential. This therefore, raises issues in relation to the possible lack of suitable IT infrastructures to support the adoption of the social media applications.

Within the current financial climate, lack of funding to invest in what could be perceived as a 'flash in the pan' innovations are a major challenge for adoption of social media applications. In order for HEI's to truly benefit from adoption of social media marketing, they need to produce a strong business-case; that would encourage the strategic management level to invest in the infrastructure, with emphasis on the cost-effectiveness of integration in the long-term, to facilitate this adoption. However, a word of caution, it would be ill advised for HEI's to use these media without having a clear strategy of what they are aiming to achieve by doing so. Adoption will also require a complete paradigm-shift of the academic staff within the HEI, the marketers role will no longer be as a broadcaster pushing content and messages at a targeted audience but as an aggregator who endeavours to pull the audience to them by means of collaboration and building of relationships within communities.

\section{REFERENCES}

1. Armstrong, J., Franklin, T.: 'A review of current and developing international practice in the use of social networking (Web 2.0) in higher education.’ (2009). Franklin Consulting, http://franklin-consulting.co.uk/

2. Barker, M., Barker, D., Bormann, N., Neher, K.: Social media marketing: A strategic approach. South-Western (2013)

3. Barnes, C.: 'B2B is still person to person'. The Marketer, Jan 2011.

4. Bonnema, J., Van der Waldt, D.L.R.: 'Information and source preferences of a student market in higher education'. International Journal of Educational Management, 22(4), 314-327. (2008)

5. Brabazon, T.:'YouTube has merit, but enough already of cat videos'. Times Higher Education. (Online Available at http://www.timeshighereducation.co.uk/story.asp?storycode=409416 (2009)

6. Brennan, R.: Should we worry about an "academic-practitioner divide" in marketing?. Marketing Intelligence and Planning, 22(5), 492-500. (2004)

7. Caemmerer, B.: The planning and implementation of integrated marketing communications. Marketing Intelligence and Planning, 27(4), 524 - 538. (2009) 
8. Callan, J.: 'Marketing's role in developing and delivering Corporate Strategy: What Vice-Chancellors really think about Marketing. London: Callan Associates (2007)

9. Campbell, H.A.: When religion meets new media, Routledge. (2010)

10. CIM: Don't stop me now: Marketing in Central Government. The Chartered Institute of Marketing (2009)

11. E-Consultancy (2009). Online PR and Social Media Trends Briefing. (Available online at http://econsultancy.com/reports/online-pr-and-social-media-trends-briefing (2009)

12. Gray, R.: 'Location is where it's at'. The Marketer, Oct 2011. (2011)

13. Gurau, C.: 'Integrated online marketing communication: implementation and management.' Journal of Communication Management, 12(2), 169-184 (2008)

14. Harris, K.: 'Using Social Networking Sites as Student Engagement Tools.' Diverse Issues in Higher Education, 25:18, 40. Retrieved from http://diverseeducation.com/\# (2008)

15. Headworth, A.:'Why twitter should be a key part of your institution's marketing strategy'. UCAS Social Media Marketing Conference, London (2010)

16. Hayes, A., McGrath, S., Campbell, J.:'Using Apps as a marketing tool’. UCAS Social Media Marketing Conference, London. (2010)

17. Hearn G., Foth, M., Gray, H.: 'Applications and implementations of new media in corporate communications: An action research approach’. Corporate Communications: An International Journal, 14:1, 49-61. (2009)

18. HigherEdExperts: 'The State of Web and Social Media Analytics in Higher Education Report' (Online Available at http://www.higheredexperts.com)(2010)

19. Hilpern, K.:'Does your marketing serve.’ The Marketer, March 2011, p.29. (2011)

20. Jadu: 'An Investigation into the Challenges, Application and Benefits of Social Media in Higher Education Institutions.' Jadu Research Report, http://www.jadu.co.uk/downloads/file/18/research_into_the_challenges_usage_and_benefits_of_social_media_in_high er_education_institutions (2010)

21. Kotler, P.: Marketing Management, (11th ed), New Jersey: Pearson Education Inc. (2003)

22. Leader-Chivee, L., Hamilton, B.A., Cowan, E.: 'Networking the Way to Success: On-line Social Networks for Workplace and Competitive Advantage.’ People and Strategy, 31(4), 40 - 46. (2008)

23. Mangold, W.G., Faulds, D.J.: 'Social media: The new hybrid element of the promotion mix.' Business Horizons, 52, 357-365. (2009)

24. Manning, C.D.: 'Part-of-Speech tagging from $97 \%$ to $100 \%$ : Is it time for some linguistics?' Chapter on Computational Linguistics and Intelligent Text Processing.' Chapter on Computational Linguistics and Intelligent Text Processing Vol 6608 of the series Lecture Notes in Computer Science pp 171-189 (2011)

25. Marken, G.A.: 'Social Media .... The Hunted Can Become the Hunter.' Public Relations Quarterly, 52(4), 9-12. (2009)

26. Matthews, D.: 'Word of Mouth.' The Marketer, November 2010, p.30 (2010)

27. McGrath, S.: "Using apps as a marketing tool - what do students want?.” Proceedings of UCAS Social Media Marketing Conference. London, pp. 21-25. (2010)

28. Other Side Notes: ' 10 ways universities can (and should) use twitter.' (Online Available at http://www.othersidenotes.com/10-ways-universities-can-and-should-use-twitter/ (2010)

29. Palmer, A., Koenig-Lewis, N.: 'An experiential, social network-based approach to direct marketing.' Direct Marketing: An International Journal, 3(3), 162-176. (2009)

30. Precedent: 'Traditional universities' websites: Trends, Observations \& Best Practice.' (Online Available at http://www.precedent.co.uk/precedent/.../the-higher-education-communication- specialists (2008)

31. Reuben, R.: 'The Use of Social Media in Higher Education for Marketing and Communications: A Guide for Professionals in Higher Education.' (Online Available at http://doteduguru.com/wp-content/uploads/2008/08/socialmedia-in-higher-education.pdf (2013)

32. Safko, L., Brake, D.K.: The Social Media Bible. John Wiley \& Sons Inc (2009)

33. Selwyn, N.: 'Social media in higher education.' The Europa World of Learning 2012, 1-10, www.educationarena.com/pdf/sample/sample-essay-selwyn.pdf (2012)

34. Sheth, J.N., Sisodia, R.S.: 'A dangerous divergence: Marketing and Society.' Journal of Public Policy \& Marketing 24(1), 160-162. (2005)

35. Singh, T., Veron-Jackson, L., Cullinane, J.: 'Blogging: A new play in your marketing game plan.’ Business Horizons, 51(4), 281 - 292. (2008)

36. Sugden, J.: 'Universities on Twitter: we'll be brief about this.' TimesOnline (Online Available at http://www.timesonline.co.uk/tol/life_and_style/education/student/article6802305.ece (2009)

37. Thomases, H.: Twitter Marketing: An Hour a Day. Indiana: Wiley Publishing Inc (2010)

38. Treadway, C., Smith, M.: Facebook Marketing: An Hour a Day. Wiley Publishing Inc (2010)

39. Weber, L.: Marketing to the Social Web. John Wiley \& Sons Inc (2009)

40. Yeshin, T.: Integrated Marketing Communications. (2nd ed) Oxford: Butterworth-Heinemann (1998) 